DEMOGRAPHIC RESEARCH

VOLUME 38, ARTICLE 43, PAGES 1303-1338

PUBLISHED 12 APRIL 2018

http://www.demographic-research.org/Volumes/Vol38/43/

DOI: 10.4054/DemRes.2018.38.43

Research Article

The direct and indirect impact of international migration on the population ageing process:

A formal analysis and its application to Poland

Agnieszka Fihel

Anna Janicka

Weronika Kloc-Nowak

(C) 2018 Agnieszka Fihel, Anna Janicka \& Weronika Kloc-Nowak.

This open-access work is published under the terms of the Creative Commons Attribution 3.0 Germany (CC BY 3.0 DE), which permits use, reproduction, and distribution in any medium, provided the original author(s) and source are given credit.

See https://creativecommons.org/licenses/by/3.0/de/legalcode. 


\section{Contents}

1 Introduction 1304

2 International migration and changes in the age structure 1304

3 Theoretical model 1308

3.1 The age-specific growth rates model 1308

3.2 The indirect effect of emigration 1311

3.3 The indirect effect of immigration 1313

$4 \quad$ Quantifying the direct and indirect effects for Poland 1314

4.1 Low fertility coinciding with intensified emigration 1314

4.2 Data used in the model 1316

$5 \quad$ Results 1318

$6 \quad$ Conclusions and discussion $\quad 1324$

$7 \quad$ Acknowledgements 1326

$\begin{array}{ll}\text { References } & 1327\end{array}$

$\begin{array}{ll}\text { Appendices } & 1335\end{array}$ 


\title{
The direct and indirect impact of international migration on the population ageing process: A formal analysis and its application to Poland
}

\author{
Agnieszka Fihel ${ }^{1}$ \\ Anna Janicka ${ }^{2}$ \\ Weronika Kloc-Nowak ${ }^{2}$
}

\begin{abstract}
BACKGROUND

The significance of mortality and fertility changes to the process of population ageing has been widely recognised in demographic research for many countries. Despite growing territorial mobility, however, the impact of international migration on changes in a population's age structure has so far been explored in a less systematic way.
\end{abstract}

\section{OBJECTIVE}

Our objective is twofold: first, to examine in a formal way the impact of international mobility on a population's age structure, and second, to estimate this impact for Poland, which is currently experiencing a coincidence of low fertility and high emigration of young persons.

\section{METHODS}

We extend the age-specific growth rates model in order to allow for the direct impact of immigration and emigration on the size of age-specific groups, as well as the indirect effect expressed in additional (in case of inflow) or 'missing' (in case of outflow) births due to international mobility.

\section{RESULTS}

Despite the massive scale of emigration from Poland, its direct impact appears to be instantaneous and smaller than that of fertility or mortality. We show that if no emigration from Poland had occurred since 1980 (i.e., for almost three decades), in 2015 the proportion of old persons would have been 1.1 percentage points lower than it actually was. The indirect effect translates into a loss of approximately $10 \%$ of births most recently, which means that it has long-term and far-reaching consequences for the population of Poland.

${ }^{1}$ Corresponding author. University of Warsaw, Poland. Email: a.fihel@uw.edu.pl.

${ }^{2}$ University of Warsaw, Poland. 


\section{CONCLUSION}

We argue that it is the indirect effect that should be the main subject of analyses concerned with international migration in the context of population ageing.

\section{Introduction}

The process of population ageing, defined as the systematic and long-term increase in the proportion of old persons ${ }^{3}$ in a population, remains one of the most important challenges for society (United Nations 2015a). The importance of fertility and mortality as determinants of this process has dominated the discussion in demographic studies on population ageing. The role of international mobility in the changes in a population's age structure has received far less attention; meanwhile, migration is a growing global phenomenon (IOM 2008).

In demographic terms, international migration affects a population directly by changing its size and age structure and indirectly by influencing the overall number of future births. While the former is instantaneous in nature, the latter has long-term and far-reaching consequences. In this study we show that international migration may exert an important long-term impact on populations and significantly affect the process of population ageing (Section 2). To this end, we extend the model of age-specific growth rates (Horiuchi and Preston 1988; Preston, Himes, and Eggers 1989) in order to allow for direct and indirect effects of immigration and emigration (Section 3). We present the application of this model to Poland (Section 4), a Central European country that is simultaneously experiencing extremely low fertility levels and high emigration rates, leading to an accelerated process of population ageing.

\section{International migration and changes in the age structure}

Fertility, mortality, and international migration are the direct determinants of changes in a population's age structure. While the effect of fertility is unequivocal and translates into shifts in the size of the youngest group, the effects of mortality and of migration are far more complex and largely depend on the age pattern of changes (Bourgeois-Pichat 1951; Coale 1956; Horiuchi and Preston 1988). For instance, if international migrants

\footnotetext{
${ }^{3}$ As the process of population ageing advances, the concept of 'old age' is moving to higher and higher ages. Alternative measures of ageing allow for constant increase in life expectancy (Sanderson and Scherbov 2010). In this study we use the threshold of 65 years to designate the lower limit of old age.
} 
are predominantly young workers their mobility contributes to population ageing in the origin country and, inversely, to population rejuvenation in the destination country. However, if the age distribution of migrants is more varied, as in the case of refugee flows, the final impact on populations' age structures remains equivocal (Vallin 2011). Of the four fundamental demographic events used in the demographic analysis - birth, death, immigration, and emigration - only birth is inseparably related to (well-defined) age, whereas the remaining three can occur at any moment in life and at any age. Thus, although permanent emigration can be compared to death as another way of leaving a resident population (cf. Preston, Heuveline, and Guillot 2001), the parallel between permanent immigration and birth as ways of entering a population is not so straightforward in the context of age structure changes.

There is a large body of research concerned with demographic determinants of population ageing. In the simplified, stylized model of demographic transition, ${ }^{4}$ the initial rejuvenating effect of a decrease in the mortality of new-borns and older children (Chesnais 1986; Coale 1956; Hermalin 1966; Lorimer 1951; Notestein 1960; Sauvy 1954 ) is subsequently neutralized by a decline in fertility (Bourgeois-Pichat 1951; Dittgen 1992; Keyfitz 1968; Notestein 1960). However, when fertility stabilizes at a low level the continuous reduction in mortality at adult and old ages becomes the driving force behind population ageing (Bengtsson and Scott 2010; Caselli and Vallin 1990; Horiuchi 1991; Preston, Himes, and Eggers 1989; Preston and Stokes 2012). Each country and region has its own specific pattern of changing age structure, ${ }^{5}$ but in general, in the countries most advanced in terms of human longevity, the process of population ageing is usually portrayed as transiting from fertility-dominated to mortality-dominated or, in terms of the population pyramid, from the bottom-oriented to the top-oriented. ${ }^{6}$

In the body of research concerned with demographic determinants of population ageing the impact of international migration has been explored in a less systematic way. We find several reasons for this. First, geographical mobility is not a phenomenon endogenous to population reproduction, unlike natality or mortality. International migration is more dependent on economic conditions, the policies pursued by countries, and sociocultural factors than the components of natural increase. And as international mobility remains irrelevant to the human population as a whole at the global level, ${ }^{7}$ it

\footnotetext{
${ }^{4}$ Where mortality decline stems from improvement in sanitary conditions and as such precedes fertility decline.

${ }^{5}$ Pool $(2005,2010)$ stresses the nonmonotonic and country-specific character of the process of population ageing, which he calls 'age-structural transition' and which results from fluctuations in birth rates and death rates; for instance, baby busts during wars and baby booms after cessation of warfare (see also Hermalin 1966).

${ }^{6}$ Lee and Zhou (2017) question this conclusion and stress the indirect effect of mortality decline, entailing a subsequent growth in births.

${ }^{7}$ At least in quantitative terms. We elaborate on this more specifically in Section 3 .
} 
does not play a significant role in demographic studies that are concerned primarily with long-term, worldwide population processes and regularities. Second, long-term data on international migration is extremely rare, so most authors studying determinants of population ageing rely on net migration rates only (Caselli and Vallin 1990; Chen 2015; Moore and Pacey 2004; Murphy 2016a; Notestein 1960; Preston, Himes, and Eggers 1989); which, as we argue in the following section, is a simplification. What is more, in the above-quoted studies the net migration rates are not derived from statistical demographic data sources but constitute residuals between the size of age-specific population groups at two points in time, and the births and deaths registered in between those points in time. Third, in a globalising world migration is becoming increasingly intensive, temporary, and repetitive (Bauman 1998), but official systems of registration fail to monitor diverse forms of international mobility, such as migration of a circular and short-lasting character. Last but not least, incorporating a rate of immigration into the model of age-specific growth rates may raise interpretational concerns, as it compares immigrants (in numerator) to a receiving population (in denominator), that is, to a population that they did not originate in. Thus, immigration is not a measure of the risk to which a receiving population is exposed (Horiuchi and Preston 1988).

Nevertheless, several studies that do allow for the effect of migration demonstrate that international mobility could both result from changes in a population's age structure and contribute to the process of population rejuvenation or ageing. On the one hand, in several studies the correlation between changes in natural increase rates and changes in emigration rates occurring 20-25 years later is found to be statistically significant and positive (Chesnais 1986; Easterlin 1961; Hatton and Williamson 1998; Kuznets 1930; Thomas 1954). ${ }^{8}$ Hatton and Williamson (1998) make the following point regarding causality: They show that a strong natural increase was one of the three most important driving factors behind $19^{\text {th }}$-century European migration overseas, ${ }^{9}$ and that the impact of this high population pressure was cumulative and long-term. The relationship between natural increase and international mobility ceased to hold true when military intervention and restrictive migration policies during the First World War effectively limited international migration in Europe and other Anglo-Saxon countries.

On the other hand, country-specific studies show that international migration occurring on a permanent basis can exert an impact on age structure because migrants are mostly young adults, ${ }^{10}$ and their arrival/departure contributes to the

\footnotetext{
${ }^{8}$ According to Chesnais (1986: 170), Ravnholt (1937) was the first to observe this relationship, for Swedish migration overseas, but his paper does not include any quantitative argumentation (see also Easterlin 1961).

${ }^{9}$ A rise in natural increase of 1 percentage point entailed a rise in the emigration rate of 0.54 p.p. 20 years later.

${ }^{10}$ This does not signify that old persons are immobile. In particular, the concept of 'retirement migration' describes mobility of affluent pensioners from highly developed countries who move abroad in search of a
} 
decrease/increase in shares of other population groups, including the share of old people (Field 2013). Alho (2008) shows a rejuvenating effect of positive net migration in simulations based on the stable population model. An elevated net outflow is empirically identified as an accelerator of population ageing in Italy (Caselli and Vallin 1990) and Sweden (Murphy 2017), whereas the excess of inflow over outflow tempered the rise in the share of old persons in France (Caselli and Vallin 1990; Dittgen 1992; Murphy 2017). Similar conclusions are drawn for internal mobility in specific highly developed countries (Chen 2015; Moore and Pacey 2004). Despite similar demographic tendencies - increasing longevity and below-replacement fertility - in European populations the ageing process was delayed (to some extent) by promoting the inflow of foreigners, as opposed to Japan, which remained relatively closed to international migrants (Lanzieri 2013).

Thus, at first international migration accelerates the process of population ageing in the sending country, while in the receiving country it postpones this process. ${ }^{11}$ In theory, the initial 'rejuvenating' effect expires if the age-specific rates of net migration remain constant in the long term or, the other way around, the rates of net migration need to increase incessantly in order to maintain a rejuvenating effect. In the long term it is not a particular level but rather changes in fertility, mortality, and migration that drive the process of ageing. ${ }^{12}$ The recent projections of so-called replacement migration - that is, immigration that only counteracts the process of population ageing - prove that such inflows to the more developed countries would need to be unrealistically large, endangering the economic, social, and cultural coherence of receiving countries (United Nations 2001; see also Bijak et al. 2007; Bijak, Kupiszewska, and Kupiszewski 2008; Kupiszewski 2013).

Most studies acknowledge that the role of international migration in changes in a population's age structure is minor (Bengtsson and Scott 2010; Caselli and Vallin 1990; Dittgen 1992; Goldstein 2009; Notestein 1960; Preston, Himes, and Eggers 1989; Murphy 2017), primarily due to the fact that in quantitative terms, migration remains modest with respect to the overall population. ${ }^{13}$ Sporadically, in specific circumstances an inflow from abroad can help to fill a generation gap, as in France, which lacked

better quality of life (Gustafson 2013; King, Warnes, and Williams 2000). The scale of this mobility is rather negligible, however.

${ }^{11}$ This rule can also be inscribed into the stylised course of demographic transition. At its early stage, when the population is relatively young and emigration exceeds immigration, international mobility accelerates (at first) the process of ageing. At its late stage, when population age and immigration exceed emigration, international mobility delays (at first) the process of ageing.

${ }^{12}$ In the European case, Murphy concludes that immigration "will accelerate population aging in the twentyfirst century if net migration does not continue the increasing trend of recent periods" (Murphy 2017: 274).

${ }^{13}$ There are some exceptions however. In West Asian countries such as Jordan, Kuwait, Qatar, Saudi Arabia, and the United Arab Emirates, all intensive labour immigration destinations, very recently (around 2015) the share of international migrants exceeded one third of the population (United Nations 2016). 
thousands of young men in the 1920s as a result of the First World War. Immigration was identified as a means of increasing the number of men of reproductive age who could become spouses and fathers in France (Henry 1966). Alternatively, from the perspective of the sending country, a massive and age-selective outflow can upset the quantitative ratios in the age structure, affecting the population's natality and demographic prospects. Identifying and measuring such long-term effects of mobility requires an advanced demographic method, and in the following we present such a model: an extended model of age-specific growth rates that allows for the impact of immigration, emigration, and concomitant changes in natality.

\section{Theoretical model}

\subsection{The age-specific growth rates model}

Demographic studies of the role of determinants of population ageing are based on methods using stable population models (Coale 1956), counterfactual projections comparing future populations under different theoretical scenarios (United Nations 2001, 1956), and, most recently, the model of age-specific growth rates (Horiuchi and Preston 1988; Preston, Himes, and Eggers 1989). ${ }^{14}$ The latter two seem similar, but the model of age-specific growth rates not only quantifies the impact of changes in fertility, mortality, and migration but also disentangles the indirect effects between these three components. The hitherto-used models were based on the net migration concept. In an extension to the model we replace the component of net migration with two separate elements related to immigration and emigration. ${ }^{15}$

The concept of net migration does not refer to a real phenomenon and is treated as a convenient simplification when no detailed data on migration is available. Distinguishing between immigration and emigration is important, however, as they may have different impacts on the demographic structure. Arrivals and departures of persons of the same age and sex are not necessarily equivalent due to, inter alia, the relationship between migration and fertility. ${ }^{16}$ If the studied country and the country of origin of potential migrants are at different stages of the demographic transition, outflow may concern individuals who are still before their childbearing years, while immigration may concern individuals who, although they are of the same age, are already past their

\footnotetext{
${ }^{14}$ Based on the earlier work by Preston and Coale (1982). See Murphy (2016b) for a comparison of these three methods.

${ }^{15}$ Preston, Himes, and Eggers (1989) and Chen (2015) use a formal notation referring separately to inflow and outflow. In the empirical analyses, however, these authors rely on the concept of net migration.

${ }^{16}$ See also footnote 20 .
} 
childbearing stage and may have arrived in the host country without their children. In this case, although the population number and age composition at the time of migration does not change, the migration processes may impact the population structure in the future.

Therefore, drawing on the model of age-specific growth rates and distinguishing in- and outflows, we allow for such an indirect effect of international migration due to possible changes in the number of births; that is, 'additional' births due to the inflow of foreign females and 'loss' of would-be births due to the outflow of national females. In this approach the effect of migration is not limited to the cohorts of mobile persons but also quantifies the changes in natality occurring in the aftermath of migration.

Following the notation of Preston and Stokes (2012) and introducing two directions of migration flow, we refer to the number of persons aged $x$ at last birthday at time $t$, denoted as $N(x, t)$. We decompose the rate of growth of the number of persons aged $x$ between times $t$ and $t+1, r(x, t, t+1)$, from the value $N(x, t)$ to the value $N(x, t+1)$ into:

$r(x, t, t+1)=\ln \frac{B(t-x+1)}{B(t-x)}+\ln \frac{p(x, t-x+1)}{p(x, t-x)}+\ln \frac{o(x, t-x+1)}{o(x, t-x)}+\ln \frac{i(x, t-x+1)}{i(x, t-x)}$,

where

- $\quad r(x, t, t+1)$ denotes the rate of growth of the population aged $x$ between times $t$ and $t+1$, i.e., $\ln \frac{N(x, t+1)}{N(x, t)}$;

- $B(t-x)$ denotes the number of births during the year ending at time $t-x$,

- $\quad p(x, t-x)$ denotes the fraction of the cohort born during the year ending at time $t-$ $x$ that survived till time $t$;

- $o(x, t-x)$ denotes the factor by which the cohort born during the year ending at time $t-x$ changed in size till time $t$ due to outflow. The value 1 means no emigration, while values smaller than 1 signify emigration. Note that this fraction is applied to the population after having accounted for the survival factor; therefore, a value equal to 0.9 means that $90 \%$ of those who have survived till time $t$ remained in the country of origin.

- $\quad i(x, t-x)$ denotes the factor by which the cohort born during the year ending at time $t-x$ changed in size till time $t$ due to inflow. The value 1 means no immigration, while values greater than 1 signify immigration. Note that this fraction is applied to the population after having accounted for both the survival and emigration factors. Therefore, a value of 1.1 means that the population increased by $10 \%$ with respect to the level observed after having accounted for deaths and outflow. 
Due to the construction of the factor $i$, which is an 'immigrant addition' to the native population at any given point in time ${ }^{17}$ the mortality of immigrants is embedded in the $i$ factor, and not in $p$ (if an immigrant dies, this will affect the population count through a change in the value of $i$ ). Consequently, in the proposed model we do not need to make any assumptions regarding the survivorship of immigrants (specifically, within this framework they can either be the same as or different from the survivorship of natives). Technically, the effect of emigration is similar to that of mortality, except for the possibility of returning (from emigration) to the country of origin. However, we will treat return migration as a separate phenomenon: By convention, we assume that it is captured in the factor $i$, and not $o$. That is, if a person aged $x$ emigrates at time $\mathrm{t}$ and then returns at time $t+k$ (at age $x+k$ ), then all the factors $o(x, t-x), o(x+1, t-x-1), \ldots$ will reflect the fact that there is one person less in the population, while the factors $i(x+k, t-x-k)$ and further on will reflect the fact that immigration has been observed. If the same individual migrates again, the $o$ (and $i$, in case of return) factors are affected again, similarly.

We will start our analysis of the effects of in- and outmigration by looking at the changes in the mean population age, $A_{p}$, using a discrete version of the framework of Preston, Himes, and Eggers (1989). As Murphy (2017) argues, although usually the median age is used as a single characteristic describing the progression of the process of ageing, the mean may also be used in this context, and permits factor decomposition. The changes in time of the mean age (the derivative with respect to time) of the population can be expressed as

$\frac{d A_{p}}{d t}=\sum_{x=0}^{\omega} r(x, t) c(x, t)\left(x-A_{p}(t)\right)$,

where $r(x, t)$ denotes the growth rate of the population aged $x$ at time $t$, and $\mathrm{c}(x, t)$ denotes the proportion of the population that is aged $x$ at time $t$. Noting from Equation 1 that the growth rate of the population may be decomposed into four rates of change related to births, mortality, in-migration, and out-migration, we may also decompose and rearrange Equation 2 to break down the changes in the mean age into components related to the four demographic factors. When identifying the effects of in- and outmigration for the process of ageing (as in the analysis for Poland in Section 4), in order

\footnotetext{
${ }^{17}$ Note that changes in the values of $o$ and $i$ for the same cohort at different points in time need not reflect any real phenomena (outflow or inflow) occurring at the time, but may be due to purely algebraic considerations. To see this, let us assume that one migrant aged $x$ arrives at time $t$ to a native population sized $N(x, t)$. In this case, the value of $i(x, t)$ will become $(1+N(x, t)) /(N(x, t))$. If, in the next period, one native aged $x+1$ dies or migrates, this same immigrant, now also aged $x+1$, will constitute a different proportional addition to the native population: $i(x+1, t+1)=(1+N(x, t)-1) /(N(x, t)-1)>i(x, t)$. Therefore, the factors $o$ and $i$ should not be interpreted as traditional immigration and emigration rates.
} 
to translate the derivative with respect to time to a discrete change between periods $t$ and $t+1$ we will use an approximated formula, averaging the age structures for $t$ and $t+1$.

Equations 1 and 2 show the immediate effects of the four components on the rate of change of the population age structure and mean age. Since we also wish to isolate the effects of flows on future births (lost or gained), we will need to pay more attention to fertility. Let us assume, then, following Lee and Zhou (2017), that the age-specific fertility (of females aged $x$ at time $t$ ) may be expressed as

$f(x, t)=\operatorname{TFR}(t) f_{o}(x)$,

where $\operatorname{TFR}(t)$ denotes the TFR at time $t$, while $f_{0}(x)$ describes the (time-invariant) age distribution of births.

In reference to Lotka's equation for the number of births (Sharpe and Lotka 1911), the total number of births from women aged $[\alpha, \beta]$ during the year ending at time $t$ may then be expressed as

$B(t)=\operatorname{TFR}(t) \sum_{x=\alpha}^{\beta} B(t-x) f_{0}(x) p(x, t-x) o(x, t-x) i(x, t-x)$.

In order to better visualize the effects of migration (without the need to treat male and female populations separately), in writing the equation above we have assumed that mortality and migration rates are equal for men and women and that the ratio of female births is equal to 0.5. However, since migration rates for men and women are significantly different we need to apply an alternative formulation and interpretation: instead of $\operatorname{TFR}(t)$ in Equation 3, in what follows we will use the gross reproduction rate (GRR) at time $t$ (denoted $F(t)$ ), and treat all the proposed formulae in the model as referring to the female (or male) population only (Lee and Zhou 2017).

\subsection{The indirect effect of emigration}

If emigration occurs, the outflow yields both a direct and an indirect effect on the age structure of the population. As for the former, if emigration occurs the number of individuals in a population diminishes by the number of those who left. As for the latter, if the emigrant is a female who is not past childbearing age, she will not give birth to any more children in the country of origin, which she may have done if she had stayed at home. In such a case, the difference between the population sizes in the case of no emigration and of emigration consists also of the number of children of the emigrant woman who were not born in the sending country. Under a simplistic 
assumption (that we propose in this section only) that there is no immigration (i.e., that $i=1$ for all age groups) and that emigrants would have had the same fertility rates if they had stayed in the country of origin, ${ }^{18}$ the difference in the number of children born by all females (aged $[\alpha, \beta]$ ) during the year ending at time $t$ amounts to

$$
\begin{aligned}
B_{o}(t)= & \sum_{x=\alpha}^{\beta} B(t-x) F(t) f_{0}(x) p(x, t-x)-\sum_{x=\alpha}^{\beta} B(t-x) F(t) f_{0}(x) p(x, t-x) o(x, t-x)= \\
& \sum_{x=\alpha}^{\beta} B(t-x) F(t) f_{0}(x) p(x, t-x)(1-o(x, t-x)) .
\end{aligned}
$$

Therefore, the age structure of the population in a scenario of no migration differs from the age structure of the population in the presence of emigration not only by the factor $o$ but also due to the fact that the number of children born to women of childbearing age is smaller, which subsequently affects the future population age structure. For example, looking at the difference in the number of individuals aged $x$ at time $t$ for the two scenarios, we have that the population aged $x$ at time $t$ is smaller by

$N_{o}(x, t)=B_{o}(t-x) p(x, t-x) o(x, t-x)$

than the hypothetical population in the case of no migration due to the lack of births by emigrant females, and by

$\Delta O(x, t)=B(t-x) p(x, t-x)(1-o(x, t-x))+B_{o}(t-x) p(x, t-x) o(x, t-x)$

overall - due to both the direct effect of emigration and the effect of no births from female emigrants. The emigration of a woman who is not past her childbearing age $(\beta)$ at the time of migration will lead to an indirect effect lasting perpetually: The number of births in the next generation will be smaller by $B_{o} \mathrm{~s}$, which (keeping all other components constant) will also lead to less births in the following generation, and so on. If a migrant who left the country before completing her childbearing period returns to the country of origin (for instance, for retirement), the return may cancel out the direct loss effect of emigration, but unless the migrant returns with all her children born abroad and their descendants, ${ }^{19}$ the indirect effect of emigration will still be observable in the population.

\footnotetext{
${ }^{18}$ Which may not always be the case (see also footnote 20 ). However, it is impossible to study what migrants would do (in terms of their family patterns) if they were not migrants.

${ }^{19}$ Following Lee and Zhou's approach (2017), we allow only for emigrant females in quantifying the number of potential births. This may be a source of interpretative problems in empirical analyses, because the indirect effect accounts for descendants of female migrants (even in mixed couples), but not for descendants of male migrants.
} 


\subsection{The indirect effect of immigration}

Immigration works in the opposite direction: The population size and structure in the immigration scenario changes with respect to the population size and structure in the no-immigration scenario, both as a direct consequence of the inflow of immigrants and due to the fact that immigrants will have children in the destination country. We may write that the number of immigrants (aged $x$ at time $t$, denoted $I(x, t))$ is equal to the total population size (aged $x$ at time $t$ ) minus the same population in the case of no immigration, i.e.,

$$
\begin{aligned}
I(x, t) & =N(x, t)-B(t-x) p(x, t-x) o(x, t-x) \\
& =B(t-x) p(x, t-x) o(x, t-x)(i(x, t-x)-1)
\end{aligned}
$$

Let us now assume that the fertility pattern for immigrants is such that the agespecific fertility (of immigrants aged $x$ at time $t$ ) may be expressed as

$f_{i}(x, t)=F_{i}(t) f_{o i}(x)$

where, just like for the native population, $F_{i}(t)$ denotes the GRR of immigrants at time $t$, while $f_{0 i}(x)$ denotes the (time-invariant) age distribution of births. In this case, the total number of children born of immigrants is equal to

$B_{i}(t)=F_{i}(t) \sum_{x=\alpha}^{\beta} I(x, t) f_{0 i}(x)$.

This signifies that the difference in the population (aged $x$ at time $t$ ) sizes in the cases of immigration and no immigration, including children born of immigrants, may be expressed as:

$\Delta I(x, t)=I(x, t)+B_{i}(t-x) p(x, t-x) o(x, t-x)$,

where we assume that children born of immigrants have the same mortality and emigration patterns as the native population.

In the special case where immigrants' fertility patterns also (instantaneously upon immigration) become identical to those observed in the native population, ${ }^{20}$ we can

\footnotetext{
${ }^{20}$ Immigrants tend to adjust their fertility patterns to those registered in the receiving countries in a relatively rapid manner, even if they originate in less developed and high-fertility societies (cf. Bengtsson and Scott 2011; Milewski 2010; Mussino and Strozza 2012; Sobotka 2008). The duration of such assimilation largely depends on the age at migration, ethnic origin, process of naturalization, and other factors. The case of migrants coming from Poland, a country of extremely low fertility, to the United Kingdom shows that
} 
write that the difference in the population size in the cases of immigration and no immigration is equal to

$$
\begin{aligned}
\Delta I(x, t)= & p(x, t-x) o(x, t-x)\left(B(t-x)(i(x, t-x)-1)+B_{i}(t-x)\right) \\
= & p(x, t-x) o(x, t-x)\left(B(t-x)(i(x, t-x)-1)+F(t-x) \sum_{y=\alpha}^{\beta} I(y, t-x) f_{0}(y)\right) \\
= & p(x, t-x) o(x, t-x)\left((i(x, t-x)-1) F(t-x) \sum_{y=\alpha}^{\beta} N(y, t-x) f_{0}(y)\right. \\
& \left.\quad+F(t-x) \sum_{y=\alpha}^{\beta} I(y, t-x) f_{0}(y)\right) \\
= & p(x, t-x) o(x, t-x) F(t-x) \sum_{y=\alpha}^{\beta} f_{0}(y)((i(x, t-x)-1) N(y, t-x)+I(y, t-x))
\end{aligned}
$$

This signifies that when researching the effect of past immigration on the population structure in the destination country at a given point in time, it is necessary to trace back the inflow until the arrival of the very first immigrant (not past childbearing age) and allow for all descendants of immigrants. ${ }^{21}$ The objective here is not to classify the descendants of immigrants (of the second, third, etc. generation) as immigrants, but to show how the population changes its size and age structure in the aftermath of immigration. Likewise, and similarly to the emigration scenario (Equations 7 and 12 work similarly), if one wishes to study the effect of present immigration on future population developments, unless all migrants arriving are already past their childbearing age (which may happen in the case of retirement return migration, for example), the effect of any immigration instance will last perpetually through the indirect channel of additional births observed.

\section{Quantifying the direct and indirect effects for Poland}

\subsection{Low fertility coinciding with intensified emigration}

While Western Europe remains the most advanced region globally in terms of demographic ageing (United Nations, 2015b), for many years this process was distorted

immigrants' fertility levels may also adapt upwards (Gołata 2016). Moreover, migration and subsequent family formation may be interrelated, especially if migration takes place due to fertility or reunion motives.

${ }^{21}$ Under the assumption that this (sub)population grows afterwards just like the native population; that is, that the intensity of births, deaths, and international mobility equals the intensity registered for native nationals. This assumption may certainly be lifted in more complex studies based on surveys concerned with the fertility and mortality patterns of immigrants and their descendants (at least the second generation). 
in Central and Eastern Europe (CEE) countries. The adult and old age mortality did not decline systematically under communist regimes, as it did in the West, ${ }^{22}$ and relatively high levels of natality and fertility persisted until the mid-1980s (Kotowska et al. 2008). Nonetheless, the emergence and prevalence of the lowest-low fertility (Kohler, Billari, and Ortega 2002) in CEE is expected to considerably intensify the process of demographic ageing. Poland, demographically the largest postcommunist country in the European Union (EU), serves as a good example: With the officially registered total fertility rate ${ }^{23}$ below 2.1 (since 1989) or below 1.3 (in the years 2002-2006 and 2013), and with life expectancy increasing steadily since 1991, in the future this country's population is expected to become one of the oldest on the continent (Eurostat 2013; United Nations 2015b).

What clearly distinguishes the demographic situation in Poland from that in other countries, however, is the most recent outflow abroad, starting in 2004 when, together with seven other CEE countries, ${ }^{24}$ it became a member of the European Union. Several massive waves of emigration have occurred in recent Polish history (Iglicka and Sword 1999); it was only in 2004, however, that Polish nationals started to gradually acquire freedom of residence in European Union countries and access to their labour markets, and emigration developed into a massive flow. While the postenlargement outflow from the Baltic States and Romania (an EU member state since 2007) was also intensive, the scale of emigration from Poland remains exceptional both in absolute and relative terms (Bruecker et al. 2009). During the period 2004-2014, more than 300,000 persons formally deregistered from their place of permanent residence in Poland and the number of Polish residents staying abroad who did not change their formal status ${ }^{25}$ increased from approximately 1 million in May 2004 to 2.4 million at the end of 2015 (GUS 2016). At the same time, the inflow and settlement of foreigners in Poland, especially Ukrainian nationals, has increased constantly since the fall of communism (Drbohlav

\footnotetext{
${ }^{22}$ Several synthetic and comprehensive analyses have been devoted to the so-called health crisis in the communist countries, resulting mostly from inefficiency in preventing and treating cardiovascular diseases (Meslé 1991, 2004; Shkolnikov, Meslé, and Vallin 1996; Valkonen 1993; Vallin and Lopez 1985; Vallin and Meslé 2001).

${ }^{23}$ It should be emphasised that official TFR estimates do not allow for a massive, long-term emigration taking place without deregistering from the place of permanent residence in Poland. As emigration mostly involves persons in the childbearing age bracket, the denominator of the TFR is therefore overestimated and the rate itself underestimated. Thus, the official statistics are probably understated by approximately $0.16-0.18$ (Gołata 2016).

${ }^{24}$ The Czech Republic, Estonia, Hungary, Latvia, Lithuania, Slovakia, and Slovenia.

${ }^{25}$ Deregistered from the place of permanent residence in Poland, which is neither obligatory nor enforceable. The official estimates of Poland's population presented by the Central Statistical Office of Poland (CSO) and reproduced by Eurostat to a large extent include emigrants who have not deregistered from their place of permanent residence in Poland, yet as most of them stay abroad for at least one year (GUS 2016), in accordance with the definition of the United Nations (1998) they should be viewed as long-term emigrants.
} 
2012). In quantitative terms, however, settlement immigration has remained marginal ${ }^{26}$ and for decades Poland has been registering a negative net migration rate.

\subsection{Data used in the model}

The analysis based on the model of age-specific growth rates, as illustrated by Equations 4 and 5, requires information on fertility, mortality, and international migration occurring in the past, from the moment the oldest living persons were born. This poses serious methodological problems for many countries and for Poland in particular, as due to large population loss, displacement, and lack of any system of registration during the Second World War (Gawryszewski 2005) there is no precise data linking the population before 1939 with that after 1945. In the first years after 1945 the territory of Poland was still inhabited by German citizens, while thousands of Polish citizens lived in territories incorporated into the Soviet Union. Given these problems, we limit our analysis to persons who survived the Second World War and were registered in the 1950 Polish population census. We reconstruct this subpopulation backwards for the period 1920-1949, using the intensity of births, deaths, and international migration registered for the general population before 1950, hereby assuming in a simplistic manner that this intensity was homogenous for all population groups in prewar Poland.

For the period 1980-2015 we account for long-term ${ }^{27}$ emigration and immigration based on different sources. First of all, we include persons who registered a change in residential status in Poland. ${ }^{28}$ For persons who did not, on the basis of Sakson (2002, see Appendix 1 for details) and population censuses (1988, 2002 and 2011; GUS 2003, 2013) we approximate migration flows (inflows and outflows) for each year between 1980 and 2011 according to information on migrants' age, sex, and year of arrival/departure registered in the most recent population census conducted in $2011 .^{29}$ Consequently, we account for emigrants who at the time of 2011 population census were abroad, and for immigrants who at the time of 2011 population census were in Poland, but not for all migrants changing their place of residence in the intercensal

\footnotetext{
${ }^{26}$ In 2011 the share of the foreign population was as low as $0.1 \%$, and of the foreign-born population (including persons born before the Second World War in territories that no longer belong to Poland) $1.8 \%$ (OECD 2013).

${ }^{27}$ Lasting at least one year.

${ }^{28}$ An individual who deregistered from a permanent stay in Poland, went abroad, and ultimately returned, adds to the outflow (in the year of departure) and the inflow (in the year of return arrival).

${ }^{29}$ The 2011 census provides information on departures and arrivals occurring before the precedent census (in 2002). Therefore, we are able to approximate the flows not only for the intercensal period (2002-2011) but also for earlier years.
} 
years. This underestimates to some extent the scale of mobility. ${ }^{30}$ Nevertheless, our approximations of emigration for the period 1980-2010 are considerably higher than the data published by the Central Statistical Office (CSO) regarding deregistrations from the place of permanent residence in Poland (Figure 1) and are comparable with other results on flows (Wiśniowski 2017) and stocks (Gołata 2012; GUS 2016). For the years 2011-2015 we use Eurostat data (2017) that seems to be corrected to account for the long-term emigration and immigration that occurs without deregistering from/registering for permanent residence in Poland. ${ }^{31}$

\section{Figure 1: Number of long-term ${ }^{1}$ immigrants and emigrants, ${ }^{2}$ 1980-2009, by period of migration (in thousands)}

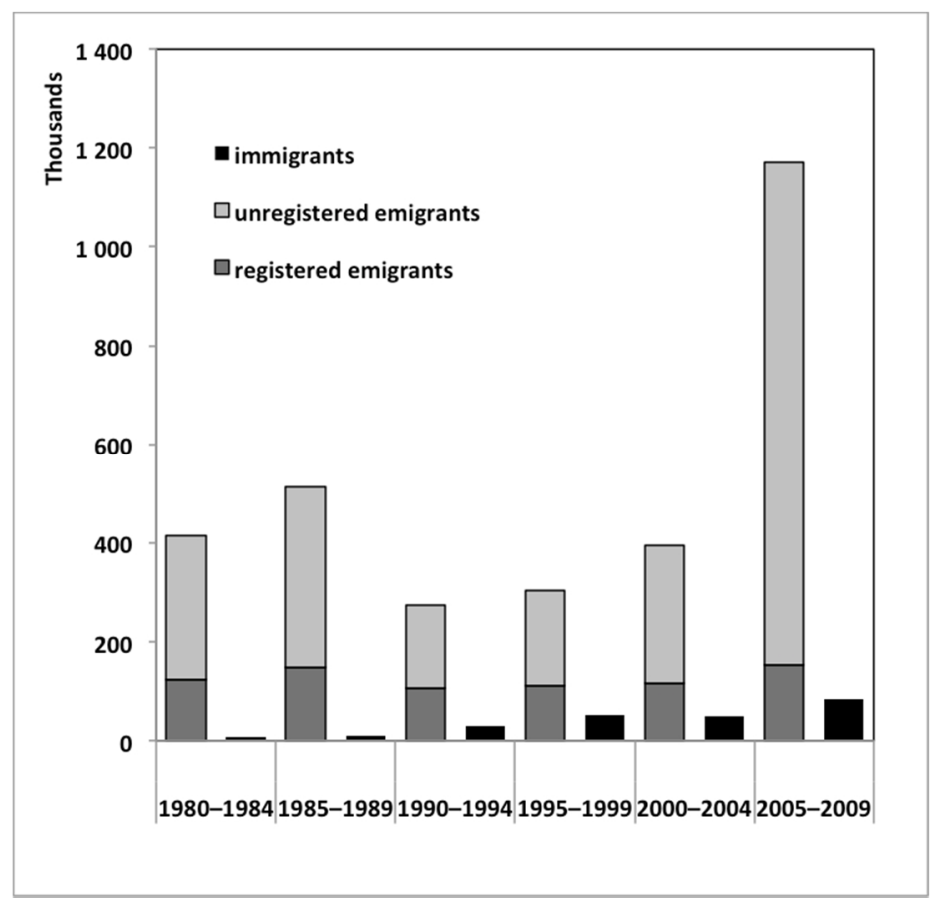

Notes: ${ }^{1}$ For at least 12 months. ${ }^{2}$ Both those who deregistered and those who did not deregister from the place of permanent residence in Poland. The number of registered emigrants comes from the population register; the number of unregistered emigrants was approximated on the basis of Sakson (2002) and population censuses and includes persons who did not return to Poland before 2011; the number of immigrants includes data from the population register and approximations based on the population censuses. Source: Own estimates based on GUS $(2003,2013,2014)$ and Sakson (2002).

${ }^{30}$ We thoroughly discuss the procedure of estimating migration flows in Poland in Appendix 2.

${ }^{31}$ There is a large break between 2008 and 2009 in the time series provided by Eurostat (2017), mostly due to the application of a different definition and methodology. 


\section{Results}

Our approximations indicate that the resident population of Poland decreased from 38 million in 1995 to 36.3 million in $2015 .^{32}$ Two main factors were responsible for the process of depopulation: the decreasing number of births and intensive emigration since the beginning of the 1980s. Indeed, if the level and age pattern of fertility had remained constant since $1985-1989^{33}$ and emigration occurred as it did, the size of the resident population would have increased to almost 40.9 million in 2015; similarly, if no emigration had taken place since 1980 (and descendants of emigrants remained in Poland) but the fertility changed as it did, the resident population as of 2015 would stand at almost 41.2 million. However, both of these assumptions seem unrealistic. As for the former, high and relatively early fertility appears to be poorly adapted to contemporary conditions of a highly competitive market economy, postmodern society, and - in the case of Poland - reduction of state assistance for families (Kotowska et al. 2008). As for the latter, the large demographic potential and considerable differences in wage levels between Poland and Western European countries were recognized as important factors stimulating the mobility of Polish nationals (cf. Bruecker et al. 2009).

The adopted framework allows us to study and decompose the growth rates for age-specific groups and the mean age into the four population components of demographic change. By convention, and similarly to other authors (cf. Caselli and Vallin 1990; Horiuchi 1991; Preston and Stokes 2012), we present the results for the most recent period, that is, for 2015 as compared to 2010. Considerable changes in the size of age-specific groups (Figure 2a) are due to the baby bust during the Second World War (i.e., for the age group 70-74), the baby boom taking place after the cessation of hostilities and lasting until around 1958, and the subsequent succession of baby busts and booms that echoed the postwar trends in natality until the most recent years (Figure 2b). The decomposition of age-specific growth rates into the four components of population change shows that fluctuation in fertility indeed explains most of the variation in the age-specific growth rates. The improvement in survival, in general, contributes to the increase in the number of persons in the old age group but not in all age groups. The so-called health crisis in Poland (1965-1990) may help explain this ambiguous effect of mortality. In this period adult male mortality increased, adult female mortality stagnated, and unfavourable health tendencies were recorded for all cohorts and age groups. ${ }^{34}$ The impact of international migration ${ }^{35}$ remains less significant than that of fertility and mortality, with immigration contributing to the

\footnotetext{
${ }^{32}$ All estimates as of January $1^{\text {st }}$.

${ }^{33}$ The TFR was on average 2.18 , whereas the mean age at birth was below 26 years.

${ }^{34}$ See footnote 22 for selected references.

${ }^{35}$ The indirect effect of international migration is not included here.
} 
increase in the number of persons aged 25-44, and emigration contributing to the decrease in the number of persons aged 5-19 and 30-64. For the 10-19 and 30-44 age groups, emigration counteracts to some extent the positive effect of fertility: Even though the number of persons in these age groups increased due to high natality during baby booms, the resultant growth rate was reduced due to the emigration of these individuals.

Figure 2: Annual age-specific growth rates, aggregate and by four components of demographic change, Poland 2010-2015
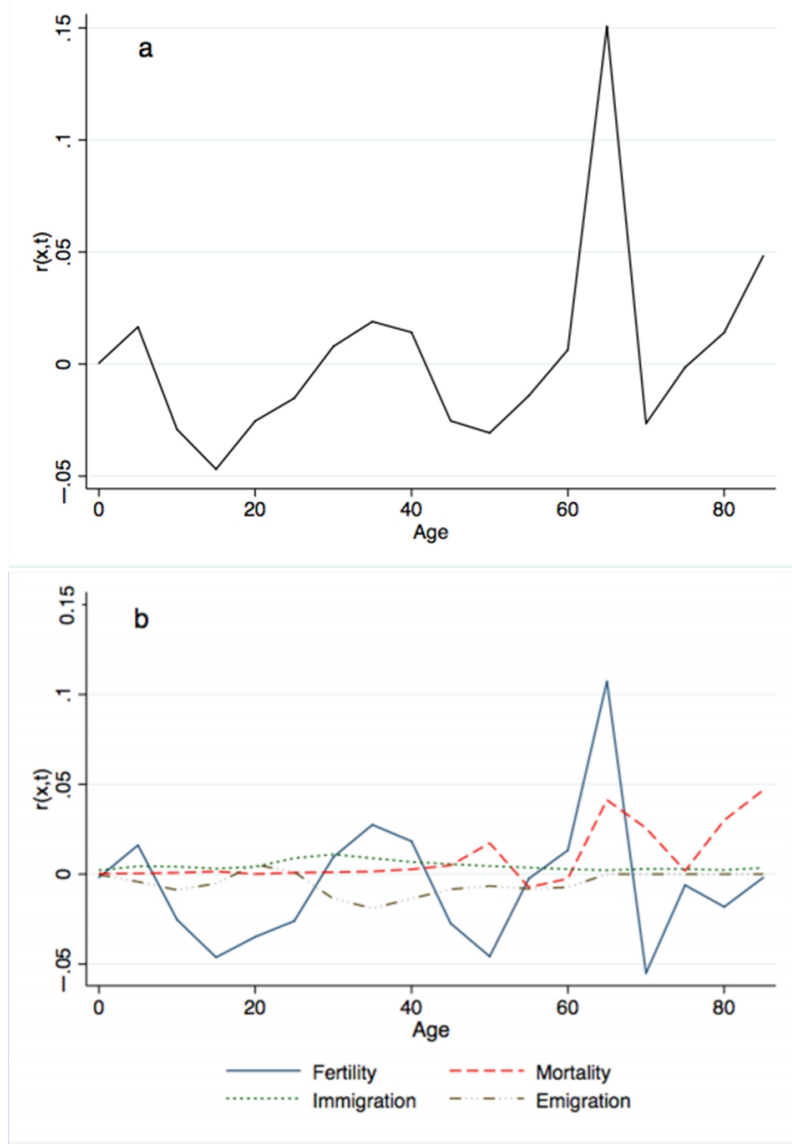

Source: Own estimates. 
The increase in the number of persons aged 65 and over (both sexes together) equalled $3.5 \%$ annually during the period $2010-2015$ and was principally driven by the improvement in mortality, which was responsible for 2.8 percentage points of this growth.

The mean age, another indicator of the process of population ageing, increased by 1.48 years for females (from 41.57 to 42.92 ) and the decline in mortality accounted for the majority of the overall change - approximately 0.80 years. The decline in the number of births was slightly less important and accounted for approximately 0.71 years in the change. The direct effects of migration flows on the average age were much smaller: Emigration led to an increase of approximately 0.04 years, while immigration rejuvenated the population by approximately 0.09 years (Figure 3 ). For males the order of importance of the first two factors is reversed: Differences in the number of births accounted for the larger part of the change between 2010 and 2015 (0.74 years out of 1.38 ), while differences in mortality accounted for 0.62 years. Again, the effect of migration flows appeared marginal ( 0.06 years and 0.03 years for inflow and outflow, respectively) and smaller than the change that could not be attributed to either of the factors. $^{36}$

Although during the last decades the outflow from Poland has been much more intensive than the inflow, the impact of immigration on the change in the average age of the population between 2010 and 2015 is more noticeable than the effects of emigration. This is a consequence of the fact that inflow (of predominantly mobile-aged individuals) on a large scale was only observed in more recent years, notably in the period 2010-2014. This had an instantaneous rejuvenating effect on the age structure of the population. Meanwhile, there has been emigration for a much longer period and its effect can be seen not only instantaneously upon departure but also in the long-term perspective. In particular, after those who left reach the mean age of the origin population, the effect of their absence rejuvenates the population of origin. If emigration flows persist, these two effects in the population - ageing due to recent emigration of the young and rejuvenation due to the absence of those who migrated a long time ago - offset each other, leading to smaller 'net' changes attributable to emigration. In general, the mean age aggregates all age-specific effects (of mortality and international migration) into one net value and therefore does not constitute a good enough indicator of the process of ageing for this kind of analyses. No single measure reveals and disentangles all age-specific effects, and analysing age-specific growth rates seems the most accurate research strategy.

\footnotetext{
${ }^{36}$ The residual accounted for 0.11 years. This error arose due to the fact that average age structures were used for the calculations.
} 
Figure 3: Changes in the mean age in the population of Poland, 2010-2015 (in years)

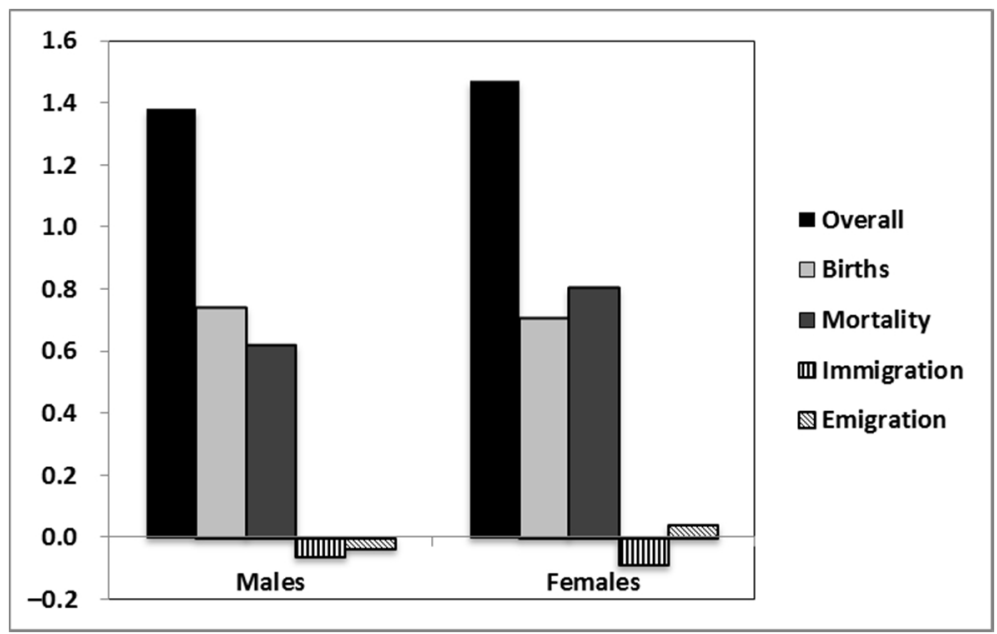

Source: Own estimates.

The decomposition presented above refers only to the direct effects of inflow and outflow. Meanwhile, as we have discussed in the previous sections, migration also affects the number of births in the years that follow. In fact, the most recent outflow, occurring since the Polish accession to the EU, appears to be highly selective with regard to age, involving mostly young adults aged 18-34 at the moment of departure (GUS 2013). Other approximations indicate that due to the emigration taking place between 2004 and the end of 2006, the loss in the 20-29 age group reached $9 \%$ overall and, in selected, more specifically defined subpopulations (i.e., dwellers of small cities aged 25-29) as much as 20\% (Okólski and Kaczmarczyk 2008). This in turn signifies that, apart from the direct effects of emigration, structural indirect effects related to 'lacking' births are significant, as the mobile cohorts are also those for which fertility levels are the highest. According to our approximations, the number of births missing due to the long-term ${ }^{37}$ emigration of Poles ${ }^{38}$ since 1980 reached 709,000 during the period 1980-2014 (681,000 children and 28,000 grandchildren, Figure 4), amounting to $4 \%$ of all births registered during that period in Poland. The most pronounced 'loss' of births was in the most recent period, 2005-2014, and equals 394,000, which is $10 \%$ of all births registered in Poland during that time.

\footnotetext{
${ }^{37}$ See notes to Figure 4.

${ }^{38}$ Or rather Polish females, as we apply the one-sex model.
} 
Figure 4: $\quad$ Approximated number of descendants (first and second generation) to Polish long-term emigrants, ${ }^{1}$ by a would-be period of birth (in thousands)

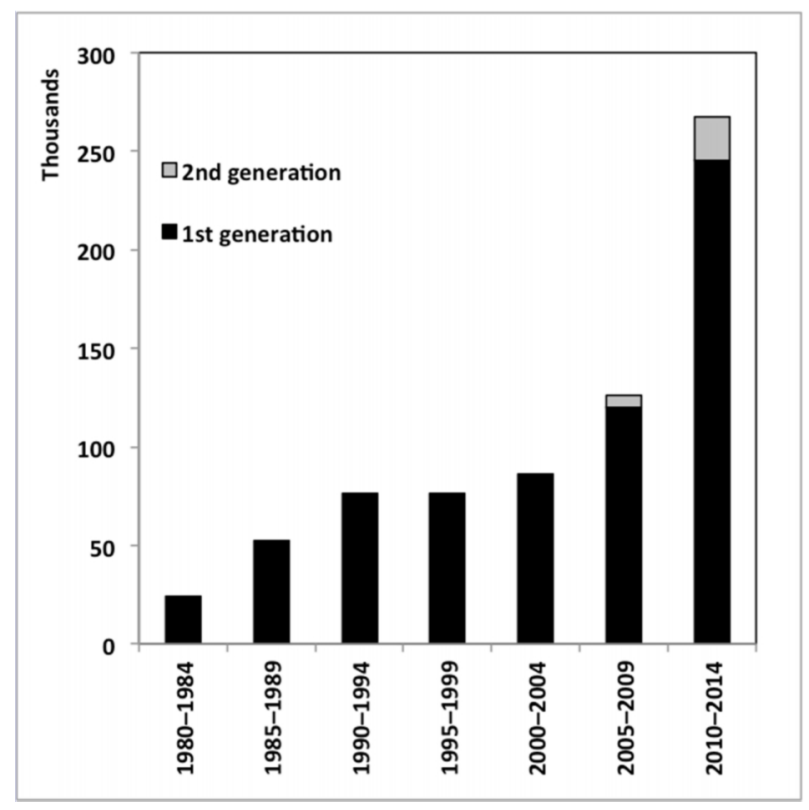

Notes: ${ }^{1}$ For at least 12 months, both those who deregistered and those who did not deregister from the place of permanent residence in Poland (but did not return before 2011).

Source: Own estimates based on GUS $(2014,2013,2003)$ and Sakson (2002).

Intensive outflow contributes to the process of ageing in Poland. The share of old persons was $16.0 \%$ in 2015 , and it would be lower, $15.2 \%$ or $14.9 \%$, if emigrants or emigrants and their descendants, respectively, had stayed in Poland after 1980 (Figure 5). Similarly, under the assumption of zero emigration since 1980, the old-age dependency ratio would equal 21.1 per 100 persons aged 15-64 instead of the actual figure of 23.7 (Figure 6). The indirect effect gained importance after 2004, when emigration started to involve mostly persons at the age of highest fertility. If the scale of emigration from Poland decreases the indirect effect will also dominate in the future, when the cumulative number of would-be descendants will start to outnumber the number of emigrants themselves. We can observe this regularity indirectly when comparing the size of age-specific groups of the resident population of Poland in 2015, under the assumption of no outflow since 1980 and the actual figures (Figure 7). The greatest difference applies to the youngest population groups, for which the indirect effect outweighs the direct effect. 
Figure 5: The percentage of persons aged 65 and over in the real population of Poland and under the assumption of zero emigration since 1980, 1985-2015 (as of 1 January)

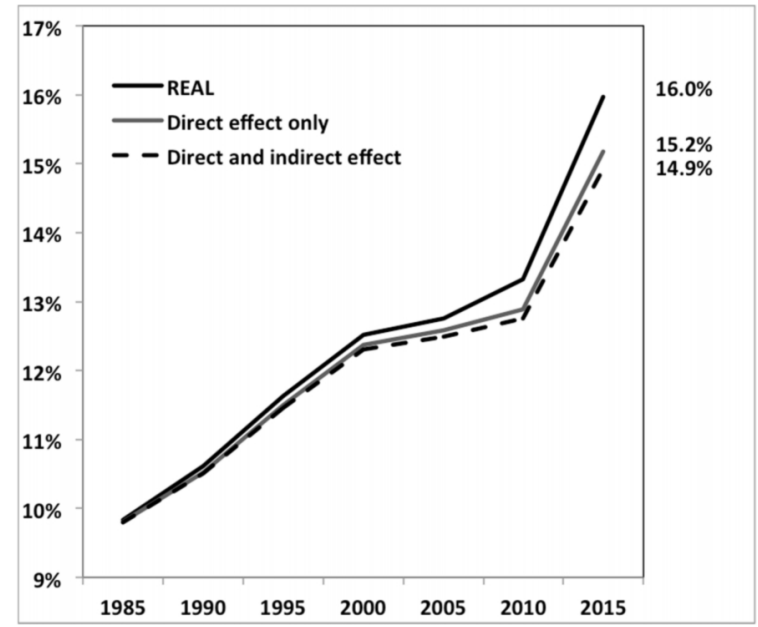

Source: Own estimates.

Figure 6: The old-age dependency ratio ${ }^{1}$ in the real population of Poland and under the assumption of zero emigration since 1980, 1985-2015 (as of 1 January)

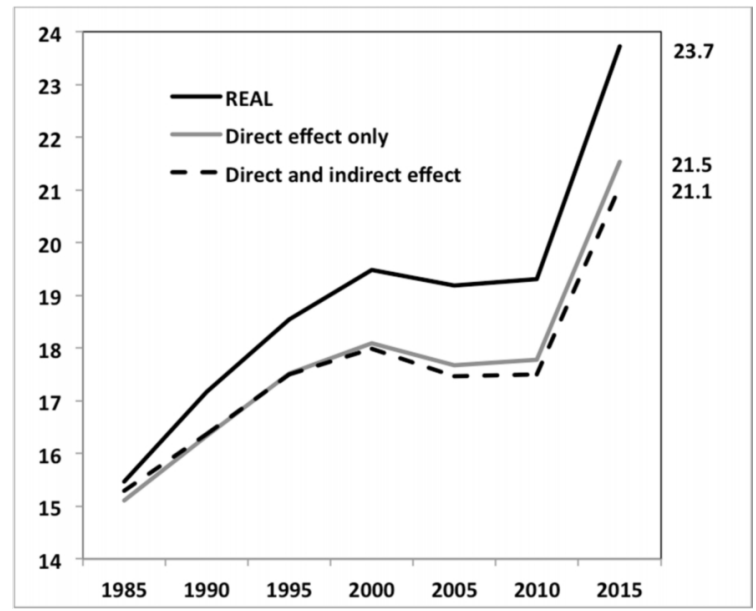

Notes: ${ }^{1}$ The number of persons aged 65 and over divided by the number of persons aged 15-64, per 100 Source: Own estimates. 
Figure 7: Ratio between age-specific groups of resident population of Poland under the assumption of zero emigration since 1980 and actual, 2015

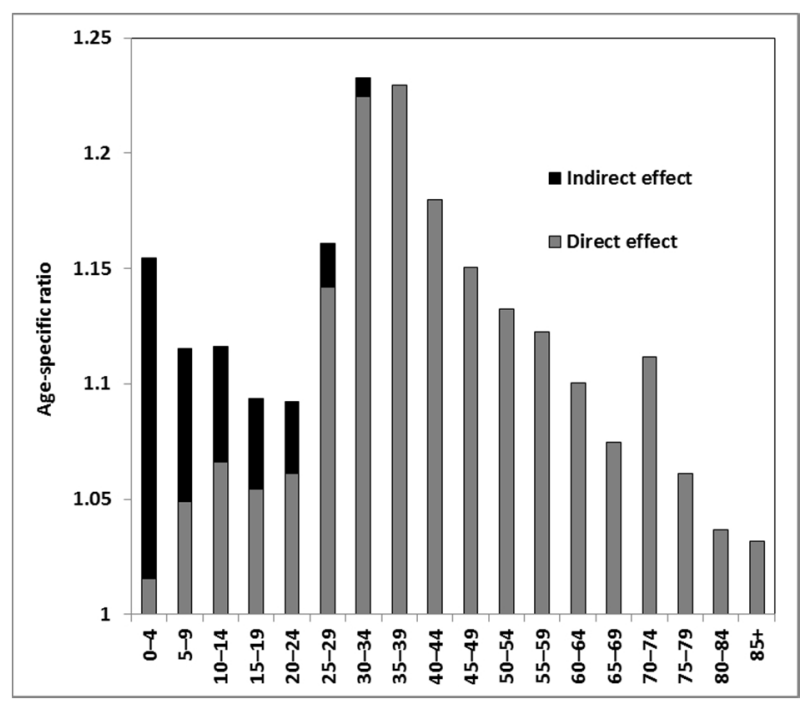

Source: Own estimates.

\section{Conclusions and discussion}

In a stylized demographic transition model, international migration exerts a less significant impact on the changes in a population's age structure than fertility and mortality. For this reason, and also due to serious methodological problems with tracking and quantifying international mobility, immigration and emigration have not been examined separately in studies based on the age-specific growth model. Nonetheless, the scale of international mobility has increased at the global level, which may affect selected populations experiencing sudden and massive flows of people. Using the age-specific growth model, we show that changes in the size of certain age groups result not only directly from international migration but also through the indirect channel of migrants' descendants.

We applied the modified age-specific growth model to the population of Poland. Despite the massive scale of emigration, its direct impact on the population's age structure appeared instantaneous in nature, inconsiderable, and visibly smaller than that of fertility or mortality. This result is in line with studies concerned with international flows in other countries and in other times. Nonetheless, it becomes evident that the 
impact of outflow will be reinforced in the future due to the indirect effect of 'missing' births and the decline in the size of future cohorts. Therefore, it is the indirect effect that should become the main subject of analyses concerned with international migration in the context of population ageing. Our analysis for Poland focuses mostly on the impact of emigration, but the formal approach that we propose can be applied to countries experiencing considerable inflows on a permanent basis (now or in the past).

Our approach omits the question of causality between international migration and fertility or mortality. Meanwhile, at the macro level, emigration may result from high population pressure in the countries of origin. Also, the process of population ageing may lead to severe labour shortages in selected economic sectors, stimulating inflow of foreign workers (OECD 2007). The interrelation between international mobility and changes in the age structure is also observed at the micro level. This signifies that to some extent the identified (direct) migration effects may also be treated as indirect effects of past mortality and fertility changes.

In our empirical analysis we assume that emigrants constitute a homogenous group, which, if it remained in the country of origin, would be characterized by the same levels of fertility and mortality as the Polish population. Such a simplistic assumption is acceptable but unnecessary, especially in an analysis focused on immigration. The model of age-specific growth rates allows for quantifying the impact of immigration under the assumption that immigrants or selected groups of immigrants have their own patterns of fertility and mortality, and their demographic behaviours change due to migration. This flexibility would also allow studying indirect effects of migration on fertility, but unfortunately the necessary data on fertility and mortality of migrants are unavailable for Poland.

An extension of the proposed framework would also allow studying indirect effects between emigration and immigration, and in particular return migration. In general, the propensity to return decreases with time (OECD 2008). If this also applies to the most recent wave of emigration from Poland, and given the fact that the scale of return migration hitherto has been relatively low (Anacka and Fihel 2012; GrabowskaLusinska and Okólski 2009), a large (and increasing) part of the outflow from Poland seems to be of a permanent nature (Janicka and Kaczmarczyk 2016). Even if some emigrants decide to return to Poland in the following decades (in particular, for retirement), their descendants will most probably remain abroad. This means that the recent emigration wave from Poland may both contribute to reducing the size of future young cohorts and to increasing the size of older cohorts, systematically accelerating the process of ageing through both of these indirect effects.

All in all, the proposed formal model, which decomposes the effect of migration into separate effects of inflow and outflow and allows studying the indirect effects of 
these phenomena, seems an important step in correctly quantifying the effect of mobility on population structure and ageing.

\section{Acknowledgements}

This study was supported by National Science Centre, Poland (Grant No. 2013/08/A/HS4/00602). The authors would like to thank Marta Anacka, Marek Okólski, Michael Murphy, Jacques Vallin, and anonymous reviewers for their kind advice and insightful comments on the paper. 


\section{References}

Alho, J. (2008). Migration, fertility, and aging in stable populations. Demography 45(3): 641-650. doi:10.1353/dem.0.0021.

Anacka, M. and Fihel, A. (2012). Selektywność emigracji i migracji powrotnych Polaków: O procesie wypłukiwania [Selectivity of emigration and of return migration of Polish nationals: On the process of washing-out]. Central and Eastern European Migration Review 1(1): 57-68.

Bauman, Z. (1998). Globalization: The human consequences. New York: Columbia University Press.

Bengtsson, T. and Scott, K. (2010). The ageing population. In: Bengtsson, T. (ed.). Population ageing: A threat to the welfare state? Berlin: Springer: 7-22. doi:10.1007/978-3-642-12612-3_2.

Bengtsson, T. and Scott, K. (2011). Population aging and the future of the welfare state: the example of Sweden. Population and Development Review 37(1): 158-170. doi:10.1111/j.1728-4457.2011.00382.x.

Bijak, J., Kupiszewska, D., and Kupiszewski, M. (2008). Replacement migration revisited: Simulations of the effects of selected population and labor market strategies for the aging Europe, 2002-2052. Population Research and Policy Review 27(3): 321-342. doi:10.1007/s11113-007-9065-2.

Bijak, J., Kupiszewska, D., Kupiszewski, M., Saczuk, K., and Kicinger, A. (2007). Population and labour force projections for 27 European countries, 2002-2052: Impact of international migration on population ageing. European Journal of Population 23(1): 1-31. doi:10.1007/s10680-006-9110-6.

Bijak, J. and Kupiszewski, M. (2013). International migration trends in Europe prior to 2002. In: Kupiszewski, M. (ed.). International migration and the future of populations and labour in Europe. Dordrecht: Springer: 57-74. doi:10.1007/97890-481-8948-9_4.

Bourgeois-Pichat, J. (1951). Évolution générale de la population française depuis le XVIIIe siècle [The overall evolution of the French population since the $18^{\text {th }}$ century]. Population (French Edition) 6(4): 635-662. doi:10.2307/1524312. 
Bruecker, H., Baas, T., Beleva, I., Bertoli, S., Boeri, T., Damelang, A., Duval, L., Hauptmann, A., Fihel, A., Huber, P., and Iara, A. (2009). Labour mobility within the EU in the context of enlargement and the functioning of the transitional arrangements. Nuremberg: Institut für Arbeitsmarkt- und Berufsforschung [electronic resource]. http://www.iab.de/de/forschung-und-beratung/projekte/ labour-mobility.aspx.

Caselli, G. and Vallin, J. (1990). Mortality and population ageing. European Journal of Population 6(1): 1-25. doi:10.1007/BF01796797.

Chen, C.-Y. (2015). The effect of migration on the mean age of population: An application of Preston's mean age of population improvement model. Journal of Family History 40(1): 92-110. doi:10.1177/0363199014562711.

Chesnais, J.-C. (1986). La transition démographique: Étapes, formes, implications économiques [Demographic transition: Stages, patterns and economic implications]. Paris: Presses Universitaires de France.

Coale, A. (1956). The effects of changes in mortality and fertility on age composition. Milbank Memorial Fund Quarterly 34(1): 79-114. doi:10.2307/3348332.

Dittgen, A. (1992). Le vieillissement de la population française: passé, présent et futur [Ageing of the French population: The past, present and future]. Espace, Populations, Sociétés 1992(1): 29-41. doi:10.3406/espos.1992.1510.

Drbohlav, D. (2012). Patterns of immigration in the Czech Republic, Hungary and Poland: A comparative perspective. In: Okólski, M. (ed.). European immigrations: Trends, structures and policy implications. Amsterdam: Amsterdam University Press: 179-210.

Easterlin, R. (1961). Influences in European overseas emigration before World War I. Economic Development and Cultural Change 9(3): 331-351. doi:10.1086/449911.

Eurostat (2013). EUROPOP 2013 [electronic resource]. Luxembourg: Eurostat. http://ec.europa.eu/eurostat/web/population-demography-migrationprojections/population-projections-data.

Eurostat (2017). Population and social conditions database [electronic resource]. Luxembourg: Eurostat. http://ec.europa.eu/eurostat/data/database.

Field, J. (2013). Migration and workforce aging. In: Field, J., Burke, R.J., and Cooper, C.L. (eds.). The SAGE handbook of aging, work and society. London: Sage: 7593. doi:10.4135/9781446269916.n5. 
Gawryszewski, A. (2005). Ludność Polski $w$ XX wieku [Population of Poland in the $20^{\text {th }}$ century]. Warsaw: IGiPZ PAN.

Gołata, E. (2012). Spis ludności i prawda [Population census and the truth]. Studia Demograficzne 1(161): 23-55.

Gołata, E. (2016). Estimation of fertility in Poland and of Polish born women in the United Kingdom. Studia Demograficzne 1 (169): 13-38.

Goldstein, J. (2009). How populations age. In: Uhlenberg, P. (ed.). International handbook of population aging. Dordrecht: Springer: 7-18. doi:10.1007/978-14020-8356-3 1 .

Grabowska-Lusinska, I. and Okólski, M. (2009). Emigracja ostatnia? [Last emigration?]. Warsaw: Wydawnictwo Naukowe SCHOLAR.

GUS (2003). Migracje zagraniczne ludności 2002 [International migration of population 2002]. Warsaw: Główny Urząd Statystyczny.

GUS (2013). Migracje zagraniczne ludności. Narodowy Spis Powszechny Ludności i Mieszkań 2011 [International migration of population. Population and households' census of 2011]. Warsaw: Główny Urząd Statystyczny.

GUS (2014). Baza demografia [Demographic database, electronic resource]. Warsaw: Główny Urząd Statystyczny. http://demografia.stat.gov.pl/bazademografia/.

GUS (2016). Informacja o rozmiarach i kierunkach czasowej emigracji z Polski $w$ latach 2004-2015 [Information on the scale and directions of temporary emigration from Poland in the years 2004-2015]. Warsaw: Główny Urząd Statystyczny.

Gustafson, P. (2013). Retirement migration. In: Ness, I. and Bellwood, P. (eds.). The encyclopedia of global human migration. Oxford: Blackwell Publishing. doi:10.1002/9781444351071.wbeghm452.

Hatton, T. and Williamson, J. (1998). The age of mass migration: Causes and economic impact. Oxford: Oxford University Press.

Henry, L. (1966). Perturbations de la nuptialité résultant de la guerre 1914-1918 [Perturbations of the nuptiality resulting from the war of 1914-1918]. Population 21(2): 273-332. doi:10.2307/1528946.

Hermalin, A. (1966). The effect of changes in mortality rates on population growth and age distribution in the United States. Milbank Memorial Fund Quarterly 44(4): 451-469. doi:10.2307/3348998. 
Horiuchi, S. (1991). Assessing the effects of mortality reduction on population ageing. Population Bulletin of the United Nations 31/32: 38-51.

Horiuchi, S. and Preston, S.H. (1988). Age-specific growth rates: The legacy of past population dynamics. Demography 25(3): 429-441. doi:10.2307/2061542.

Iglicka, K. and Sword, K. (eds.) (1999). The challenges of East-West migration for Poland. London: Macmillan. doi:10.1007/978-1-349-27044-6.

IOM (2008). World migration report 2008: Managing labour mobility in the evolving global economy. Geneva: IOM. doi:10.18356/2c43fld0-en.

Janicka, A. and Kaczmarczyk, P. (2016). Mobilities in the crisis and post-crisis times: migration strategies of Poles on the EU labour market. Journal of Ethnic and Migration Studies 42(10): 1693-1710. doi:10.1080/1369183X.2016.1162350.

Kaczmarczyk, P. (ed.) (2015). Recent trends in international migration in Poland: The 2013 SOPEMI report. Warsaw: University of Warsaw, Centre of Migration Research (CMR working papers 84/144).

Keyfitz, N. (1968). Introduction to the mathematics of population. Reading: AdisonWesley.

King, R., Warnes, T., and Williams, A.M. (2000). Sunset lives: British retirement migration to the Mediterranean. Oxford: Berg.

Kohler, H.-P., Billari, F., and Ortega, H.A. (2002). The emergence of lowest-low fertility in Europe during the 1990s. Population and Development Review 28(4): 641-680. doi:10.1111/j.1728-4457.2002.00641.x.

Kotowska, I., Jóźwiak, J., Matysiak, A., and Baranowska, A. (2008). Poland: Fertility decline as a response to profound societal and labour market changes? Demographic Research 19(22): 795-854. doi:10.4054/DemRes.2008.19.22.

Kupiszewski, M. (ed.) (2013). International migration and the future of populations and labour in Europe. Dordrecht: Springer Science and Business Media. doi:10.1007/978-90-481-8948-9.

Kuznets, S. (1930). Secular movements in production and prices: Their nature and their bearing upon cyclical fluctuations. Boston: Houghton Mifflin.

Lanzieri, G. (2013). Long-term contribution of migration in ageing populations: Japan compared with Europe. Luxembourg: Publications Office of the European Union (Statistical working papers). doi:10.2785/29184. 
Lee, R. and Zhou, Y. (2017). Does fertility or mortality drive contemporary population aging? The revisionist view revisited. Population and Development Review 43(2): 285-301. doi:10.1111/padr.12062.

Lorimer, F. (1951). Dynamics of age structure in a population with initially high fertility and mortality. Population Bulletin of the United Nations 1: 31-41.

Meslé, F. (1991). La mortalité dans les pays d'Europe de l'Est [Mortality in the countries of Eastern Europe]. Population 46(3): 599-649. doi:10.2307/1533408.

Meslé, F. (2004). Mortality in Central and Eastern Europe: Long-term trends and recent upturns. Demographic Research Special Collection 2(3): 45-70. doi:10.4054/DemRes.2004.S2.3.

Milewski, N. (2010). Immigrant fertility in West Germany: Is there a socialization effect in transitions to second and third births? European Journal of Population 26(3): 297-323. doi:10.1007/s10680-010-9211-0.

Moore, E.G. and Pacey, M.A. (2004). Geographic dimensions of aging in Canada, 1991-2001. Canadian Journal on Aging / La Revue Canadienne Du Vieillissement 23(supplement): 5-21.

Murphy, M. (2016a). The impact of migration on long-term European population trends, 1950 to present. Population and Development Review 42(2): 225-244. doi:10.1111/j.1728-4457.2016.00132.x.

Murphy, M. (2016b). Demographic determinants of population ageing in European countries. Paper presented at the Conference of European Statisticians, Economic Commission for Europe, Geneva, Switzerland, April 20, 2016.

Murphy, M. (2017). Demographic determinants of population aging in Europe since 1850. Population and Development Review 43(2): 257-283. doi:10.1111/padr.12073.

Mussino, E. and Strozza, S. (2012). The fertility of immigrants after arrival: The Italian case. Demographic Research 26(4): 97-130. doi:10.4054/DemRes.2012.26.4.

Notestein, F. (1960). Mortality, fertility, the size-age distribution and the growth rate. In: National Bureau of Economic Research (ed.). Demographic and economic change in developed countries. Princeton: Princeton University Press: 261-284.

OECD (2007). International migration outlook. Paris: OECD Publishing. doi:10.1787/migr_outlook-2007-en. 
OECD (2008). International migration outlook. Paris: OECD Publishing. doi:10.1787/migr_outlook-2008-en.

OECD (2012). Connecting with emigrants: A global profile of diasporas 2012. Paris: OECD Publishing.

OECD (2013). International migration outlook 2013. Paris: OECD Publishing. doi:10.1787/migr_outlook-2013-en.

OECD (2015). Connecting with emigrants: A global profile of diasporas 2015. Paris: OECD Publishing. doi:10.1787/9789264239845-en.

Okólski, M. (1992). People on the move: New migration flows in Europe. Strasbourg: Council of Europe.

Okólski, M. and Kaczmarczyk, P. (2008). Demographic and labour-market impacts of migration on Poland. Oxford Review of Economic Policy 24(3): 599-624. doi:10.1093/oxrep/grn029.

Pool, I. (2005). Age-structural transitions, population waves and 'political arithmetick'. In: Tuljapurkar, S., Pool, I., and Prachuabmoh, V. (eds.). Population resources and development: Riding the age waves. Dordrecht: Springer: 3-10. doi:10.1007/1-4020-3464-4_1.

Pool, I. (2010). Age-structural transitions in industrialized countries. In: Tuljapurkar, S., Ogawa, N., and Gauthier, A. (eds.). Ageing in advanced industrial states: Riding the age waves. Dordrecht: Springer: 3-22. doi:10.1007/978-90-481-3553-0_1.

Preston, S.H. and Coale, A. (1982). Age structure, growth, attrition, and accession: A new synthesis. Population Index 48(2): 217-259. doi:10.2307/2735961.

Preston, S.H., Heuveline, P., and Guillot, M. (2001). Demography: Measuring and modeling population processes. Oxford: Blackwell.

Preston, S.H., Himes, C., and Eggers, M. (1989). Demographic conditions responsible for population aging. Demography 26(4): 691-704. doi:10.2307/2061266.

Preston, S.H. and Stokes, A. (2012). Sources of population aging in more and less developed countries. Population and Development Review 38(2): 221-236. doi:10.1111/j.1728-4457.2012.00490.x.

Ravnholt, H. (1937). Quantitative concept of the international mobility of population. In: Congrès international de la population (eds.). Théorie générale de la population. Paris: Hermann: 224-229. 
Sakson, B. (2002). Wpływ 'niewidzialnych' migracji zagranicznych lat osiemdziesiatych na struktury demograficzne Polski [The impact of 'invisible' international migration of the 1980s on the demographic structures of Poland]. Warsaw: Szkoła Główna Handlowa (Monografie i Opracowania).

Sanderson, W.C. and Scherbov, S. (2010). Remeasuring aging. Science 329(5997): 1287-1288. doi:10.1126/science.1193647.

Sauvy, A. (1954). Le vieillissement des populations et l'allongement de la vie [The ageing of populations and lengthening of life]. Population (French Edition) 9(4): 675-682. doi:10.2307/1524921.

Sharpe, F.R. and Lotka, A.J. (1911). A problem in age-distribution. Philosophical Magazine Series 6 21(124): 435-438. doi:10.1080/14786440408637050.

Shkolnikov, V., Meslé, F., and Vallin, J. (1996). Health crisis in Russia: I. Recent trends in life expectancy and causes of death from 1970 to 1993. Population (English selection) 8(1996): 123-154.

Sobotka, T. (2008). The rising importance of migrants for childbearing in Europe. Demographic Research 19(9): 225-248. doi:10.4054/DemRes.2008.19.9.

Thomas, B. (1954). Migration and economic growth: A study of Great Britain and the Atlantic economy. Cambridge: Cambridge University Press.

United Nations (1956). The aging of populations and its economic and social implications. New York: United Nations.

United Nations (1998). Recommendations on statistics of international migration, revision 1. New York: United Nations.

United Nations (2001). Replacement migration: Is it a solution to declining and ageing populations? New York: United Nations.

United Nations (2015a). World population ageing 2015. New York: United Nations.

United Nations (2015b). World population prospects, the 2015 revision [electronic resource]. New York: United Nations. https://esa.un.org/unpd/wpp/.

United Nations (2016). International migration 2015 [wall chart]. New York: United Nations.

Valkonen, T. (1993). Socio-economic mortality differences in Europe. The Hague: Netherlands Interdisciplinary Demographic Institute NIDI (NIDI Hofstee Lecture Series 1). 
Vallin, J. (2011). Vieillissement de la population [Population ageing]. In: Meslé, F., Toulemon, L., and Véron, J. (eds.). Dictionnaire de démographie et des sciences de la population [Dictionary of demography and of population sciences]. Paris: Armand Collin: 506-508.

Vallin, J. and Lopez, A. (eds.) (1985). Health policy, social policy and mortality prospects. Paris: INED, IUSSP.

Vallin, J. and Meslé, F. (2001). Évolution de la mortalité en Europe depuis 1950: Mortalité par âge, sexe et causes de décès [Evolution of mortality in Europe since 1950: mortality by age, sex, and causes of death]. In: Council of Europe (ed.). Tendances en matière de mortalité et mortalité différentielle [Trends in mortality and in mortality disparities]. Strasbourg: Council of Europe Publishing: $33-188$.

Wiśniowski, A. (2017). Combining Labour Force Survey data to estimate migration flows: The case of migration from Poland to the UK. Journal of the Royal Statistical Society Series A 180(1): 185-202. doi:10.1111/rssa.12189. 


\section{Appendix 1: International migration in Poland in the 1980s}

In communist times, a uniform and specific migration registration system called SERP (System Ewidencji Ruchu Paszportowego, passport traffic recording system) was introduced in Poland to control international mobility. Like in other communist Central and Eastern European countries, this police system imposed strict controls on citizens and therefore the data on international migration in this period is considered to be of very good quality. The system was precise, complete, and linked to the population register. Departure from Poland or a return to Poland was not possible without registering at the border, and the departure date, return date, and personal and sociodemographic characteristics of migrants were recorded. All international travel required special permission and a two-piece voucher; one piece was handed to the border guard at the moment of departure and the other upon return.

The data gathered by SERP was confidential, but aggregate results were published in 1988 in a report by the Government Population Council of Poland (Rzadowa Rada Ludnościowa). Before individual data from the SERP register was destroyed, Sakson (2002) managed to use aggregate results (without personal information) and calculate the number of persons who left Poland in the period 1981-1988 and had not returned by 1988 by year of departure, country of destination, and demographic characteristics. The SERP data is considered to be of very good quality (Okólski 1992), which is often the case with sources from communist countries. With the re-introduction of democratic rule and a profound liberalization of migration policy, the SERP system was closed down and administrative sources ceased to capture a large part of emigration from Poland (Bijak and Kupiszewski 2013). 


\section{Appendix 2: The procedure of international migration approximation}

In our analysis we wanted to focus on long-term international migration that may have a sustainable impact on the population's age structure, and to account for both emigrants who did not return and immigrants who settled in Poland. For migration in the 1980s we used information from Sakson's (2002) analysis (see Appendix 1), and for the 1990s and 2000s we used the 2002 and 2011 population censuses. Thus, we only accounted for persons who registered in/deregistered from their place of permanent residence in Poland (and not for all migrants changing their place of residence in the intercensal years), and additionally approximated long-term migration flows occurring without registration in/deregistration from the place of permanent residence in Poland.

According to the 2002 population census, 626,000 persons (permanent residents of Poland) left Poland and had not returned by 2002, of whom 449,000 left Poland between 1989 and 2002 (sex, age at time of departure, and exact year of departure are known), 98,000 left before 1989, and no departure date information is available for 79,000. Persons who left before 1989 were excluded from our further approximation in order to avoid double-counting them (as very probably they were included in Sakson's estimates (2002)). Seventy-nine thousand persons, for whom no information is available, were redistributed across years of departure, proportionally to the distribution of migrants for whom the departure date was provided (including those who left before 1989).

The same procedure was applied to approximate the scale of emigration between 2002 and 2010, on the basis of the 2011 population census. The information about the sex, age at time of departure, and exact year of departure is available for 32,000 persons who left before 2002 (excluded to avoid double-counting) and 202,000 persons who left between 2002 and 2010. No information about the year of departure is available for as many as 619,000 persons (83\%). Again, we redistributed these persons across the departure years proportionally to the distribution of all migrants for whom information does exist (including those who left before 2002, according to the 2011 census).

The proportional method of redistribution of migrants for whom there is no information about the exact date of departure may result in important over- or underestimation. It is very plausible that the share of emigrants who left Poland a long time ago is higher among persons with missing data in both the 2002 and 2011 censuses. However, if we were to assume that persons for whom no information is available in either of the censuses (79,000 and 619,000 respectively) left before 1988, we would conclude that the flows in the 1980s were more considerable than those in the 2000s. This is absolutely unrealistic and contrary to all other estimates, which indicate that the outflow from Poland intensified most recently, especially after 2004. Estimates 
by the CSO of Poland, based on the results of Polish population registers, receiving countries' statistics, and labour force surveys (GUS 2016), show that the number of persons remaining abroad increased from 1 million in May 2004 (counting stays of at least two months) to 2 million at the end of 2010 (stays of at least three months), and 2,515,000 at the end of 2016 (stays of at least three months). According to these estimates, the majority of migrants (80\%) are long-term, staying abroad for at least 12 months. The OECD $(2012,2015)$ presents similar emigration dynamics, although it refers only to the stock of Polish-born emigrants living abroad, which is estimated to have increased from 2,393,000 in 2000 to 2,849,000 in 2005/2006 and 3,339,000 in 2010/2011. Wiśniowski's (2017) estimates of annual flows from Poland to the United Kingdom alone increase from approximately 50,000 in 2003 to 250,000 in 2006. Thus, our proportionate redistribution of migrants by year of departure gives very 'careful' approximations that are in line with the increase in the number of Polish nationals residing abroad estimated by the CSO (GUS 2016). While our redistribution procedure shows a flow of 1,018,000 between 1 January 2005 and 31 December 2009, according to the CSO the number of Poles residing abroad increased by 1,100,000 between May 2004 and December 2009.

The procedure applied to approximate the scale of immigration (inflow of foreign citizens), based on population censuses, was the same as in the case of emigration. The population census of 2011 underestimates the scale of inflow, revealing the presence of only 55,400 foreign citizens in Poland. This result is reproduced in the Eurostat Population database and the OECD International Migration database. Unfortunately, no other source of data seems to reflect the scale of immigration in a reliable way. The Labour Force Survey shows that in 2011 more than 40,000 foreign citizens aged 15 and over were living in Poland. According to official registers, as of 31 December 2010 97,000 foreign citizens held valid permits of stay in Poland (of all kinds), mostly permits to settle (almost 48,000) or for a fixed period (over 37,000, Kaczmarczyk 2015). This source of information does not reflect the true stock of immigrants living in Poland either, and should be reinforced by administrative data from the main sending countries (Ukraine in particular). But if we assume that the last mentioned source does reflect the true scale of permanent immigration, being approximately $76 \%$ higher than the numbers from the 2011 population census, this would have some impact on our calculations. Higher immigration would appear to postpone the process of ageing: The mean age of the population (both sexes combined) between 2010 and 2015 would increase by 1.38 years instead of 1.42 years, and the contribution of immigration would be -0.11 years instead of -0.07 years. If we focus on immigration only the result is indeed visibly different, but if we keep in mind the overall role of the four demographic factors of population ageing the primary significance of natality and mortality remains unquestionable. 
Nonetheless, long-term immigration to Poland is generally considered to remain at a relatively low level, while the vast majority of inflow takes place on a short-term basis. Although short-term immigration has intensified in the most recent years (since 2008), mostly due to the simplification of administrative procedures for employing short-term labour migrants from Eastern countries (Armenia, Belarus, Georgia, Moldova, the Russian Federation, and Ukraine), we ignore it, as short-term mobility does not exert a long-term impact on population ageing. 